\title{
Actual cost of providing long-acting reversible contraception: a study of Implanon ${ }^{\circledR}$ cost
}

\author{
Clare Lipetz, Ceri Phillips, Charlotte Fleming
}

\begin{abstract}
Background The National Institute for Health and Clinical Excellence (NICE) has judged Implanon ${ }^{\circledR}$ to be the most cost effective of the long-acting reversible contraception (LARC) methods, and its cost effectiveness is enhanced with increased duration of use. Gwent Sexual and Reproductive Health service provides unrestricted use of Implanon, and with the number of implants fitted increasing annually the service wanted to know how long clients were keeping their contraceptive implants in and the cost of implant provision.
\end{abstract}

Methods The actual cost of providing Implanon was calculated in a cohort of 493 patients within a communitybased sexual and reproductive health service, and compared to that predicted in the NICE Clinical Guideline 30 on LARC.

Results The annual cost for the method (using Implanon) was $£ 77.49,25 \%$ lower than the estimate made by NICE, despite a shorter duration of use of the method.

Conclusion The actual cost in this community-based sexual and reproductive health service may not be transferable to other settings such as general practice.

Keywords cost analysis, Implanon ${ }^{\circledR}$, LARC, long-acting reversible contraception

J Fam Plann Reprod Health Care 2009; 35(2): 75-79

(Accepted 26 August 2008)

\section{Introduction}

Clinical Guideline 30 on long-acting reversible contraception (LARC) ${ }^{1}$ produced by the National Institute for Health and Clinical Excellence (NICE) ranked the 3year subdermal etonogestrel implant, Implanon ${ }^{\circledR}$, the most cost effective with cost effectiveness enhanced with increased duration of use. Gwent Sexual and Reproductive Health (GSRH) service provides unrestricted use of Implanon and numbers fitted have increased from 461 in 2002-2003 to around 1400 in 2007-2008. We needed to know how long clients were keeping their contraceptive implants in and the cost of implant provision.

The service is available to a population of 109000 females aged between 15 and 44 years. There are 34000 contraceptive attendances per annum, approximately 4000 attendances per whole-time equivalent in the service. The service provides 50 clinics per week at 31 different sites. Five Local Health Boards use the GSRH service with both rural and urban populations and areas of high social deprivation. The service has some of the highest teenage pregnancy and abortion rates in Wales. ${ }^{2}$

\section{Methods}

The case notes of all patients who had Implanon fitted in 2003 in Gwent clinics were reviewed, from insertion to removal, up to 36 months. Missing information was collected by contacting patients, where consent had been given, with a questionnaire, either directly with the patient or via the general practitioner (GP).

The information recorded was:

- Duration of use of the implant (1-36 months)

- Number of pregnancies during use of Implanon

\section{Community Gynaecology and Sexual Health, Gwent}

Healthcare NHS Trust, Cwmbran, UK

Clare Lipetz, MRCOG, MFSRH, Consultant

Charlotte Fleming, MD, MRCOG, Clinical Director

Institute of Health Research, School of Health Science,

Swansea University, Swansea, UK

Ceri Phillips, PhD, Professor

Correspondence to: Dr Clare Lipetz, Community Gynaecology and Sexual Health, Gwent Healthcare NHS Trust, Llanyrafon House, Llanfrechfa Grange, Cwmbran, Torfaen NP448YN, UK.

E-mail: clare.lipetz@gwent.wales.nhs.uk

\section{Key message points}

- The actual cost of Implanon ${ }^{\circledR}$ provision is $25 \%$ lower than the National Institute for Health and Clinical Excellence (NICE) cost estimate in a community service and is likely to be reduced further with expansion of nurse-led services.

- Side effects of Implanon may be treated with little increase to cost of provision.

- Cost effectiveness analysis of long-acting reversible contraception (LARC) should include actual provision costs and typical continuation rates.

- Number of visits to a doctor or nurse during use of the method for problems associated with the method

- Prescribing costs for treatment of side effects.

The cost analysis was calculated per patient. This included number of visits, costs of type of visit and prescriptions for side effects. Indirect costs (e.g. training) were shared by the cohort. For those patients with incomplete duration of use data, costs were ascribed as a minimum cost for insertion and removal.

We excluded 28 patients who could not be fully identified. Patients who had requested no contact with them or their GP were treated as lost to follow-up. Minors, looked-after children or those known to be illiterate were not contacted. Those lost to follow-up were costed as those with incomplete duration of use data. A summary of patient numbers is given in Table 1 .

The relevant information was obtained from finance, pharmacy and supplies departments. The costs of surgical termination of pregnancy (STOP), a live birth and a general anaesthetic removal of Implanon were not obtainable at a local level and so we used the NICE tariff. ${ }^{3}$ The annual cost of the method was calculated based on 2005 costs and compared to the NICE Guideline costs.

\section{Results}

A total of 493 notes were retrieved, 400 of which had complete duration of use data $(81 \%)$ over the 3 -year period. Some 9701 months of Implanon use was recorded (equivalent to 808 woman-years).

\section{Duration of use}

Implanon use was recorded in months. Continuation rates 


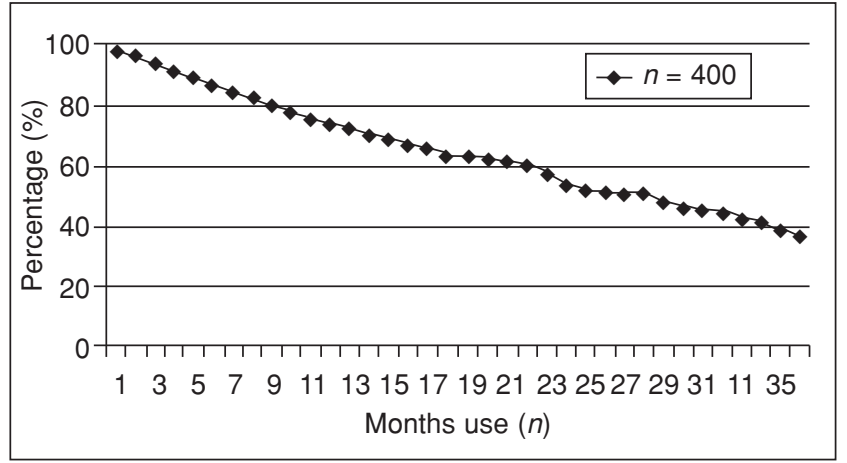

Figure 1 Continuation rates of Implanon ${ }^{\circledR}$ use for the period 2003-2006

per month are shown in Figure 1. Duration of use was not known in $19 \%$ (93) of patients. In the known use group $(n=400), 27 \%$ (108) were removed in the first year $(1-12$ months), $37 \%$ (148) were retained to the expiry date giving a discontinuation rate of $63 \%$ over 3 years. Thirty percent (147) of patients had their implant removed for side effects. Of these, 68\% (100) did not receive a treatment for their side effects. Average duration of use in Gwent was 2.02 years $(n=400)$ and this was used as the denominator for the calculation of annual cost of the method.

\section{Direct costs}

\section{Medical}

In 2003, Gwent provided 50 relevant contraceptive clinic sessions, of which 47 were staffed by staff grade doctors and three by consultants. The actual length of consultations for removal and insertion has been measured as part of local work within our service on mapping the patient pathway through clinic (Table 2). ${ }^{4}$

The average cost per session was calculated as: $47 \mathrm{x}$ $£ 149.15$ (staff grade session) and $3 \times £ 221.44$ (consultant session). Total: $£ 7674.37 / 50=£ 153.48$ per clinician session. Session of 210 minutes: cost per minute $=£ 0.73$.

\section{Nurse}

All nurses present at the 50 clinics were working as F Grades in 2003 (Band 6). One session is 210 minutes at $£ 77.87$. Cost per visit of 15 minutes $=£ 5.56$. The cost of a nurse chaperone for the removal visit (22 minutes) was $£ 8.16$.

\section{Pack costs}

The equipment cost for insertion was $£ 0.56$ and for removal was $£ 2.41$ as detailed in Table 3 and reflecting local service practice.

Table 1 Summary of case notes used

\begin{tabular}{lr}
\hline Parameter & $\boldsymbol{n}$ \\
\hline Implanon ${ }^{\circledR}$ insertions identified on database & 521 \\
Case notes excluded (unidentified) & 28 \\
Total case notes in cohort & 493 \\
Number of notes retrieved & 493 \\
Complete duration of use data & 400 \\
Lost to follow-up & 16 \\
\hline
\end{tabular}

Table 2 Duration and cost of different types of visit

\begin{tabular}{lll}
\hline Type of visit & $\begin{array}{l}\text { Duration of } \\
\text { visit (minutes) }\end{array}$ & $\begin{array}{l}\text { Cost of doctor's } \\
\text { time }(\boldsymbol{\Sigma})\end{array}$ \\
\hline Insertion & 16 & 11.68 \\
Removal & 22 & 16.08 \\
Other visit & 15 & 10.96 \\
\hline
\end{tabular}

Table 3 Cost of consumables for Implanon ${ }^{\circledR}$ insertion and removal

\begin{tabular}{ll}
\hline Procedure/consumables & Cost $(£)$ \\
\hline Implanon insertion & \\
Sterets $\times 2$ & 0.05 \\
Swabs $(1$ pack $5 \times 5 \mathrm{~cm})$ & 0.04 \\
Bandage & 0.48 \\
Total & 0.57 \\
Implanon removal & \\
Sterets $\times 2$ & 0.05 \\
Swabs $(2$ packs $5 \times 5 \mathrm{~cm})$ & 0.08 \\
Pack & 0.34 \\
Syringe & 0.03 \\
Needle & 0.01 \\
Blade & 0.19 \\
Lidocaine & 0.28 \\
Tisept & 0.26 \\
Steristrips & 0.69 \\
Bandage & 0.48 \\
Total & 2.41 \\
\hline
\end{tabular}

\section{Implanon cost}

The unit cost of the implant was $£ 89.46$.

\section{Prescribing costs of treatments}

Some $46 \%$ (229) of patients experienced no side effects. Of the $29 \%$ (141) of patients who complained of bleeding problems, $52 \%$ (73) were prescribed a treatment. The most common treatments were the combined oral contraceptive pill (COC) $(n=31)$ and mefenamic acid $(n=25)$. Other prescriptions were for the progestogen-only pill $(n=6)$ and tranexamic acid $(n=3)$. No patients were prescribed antibiotics.

The actual cost of prescriptions was calculated and if the duration of the prescription was not clear from the notes, a 3-month $(3 \times 21)$ pack of COC or 28-tablet pack of mefenamic acid was assumed.

Pregnancy tests during the period of Implanon prescription were also costed at $£ 0.65$ per test.

\section{Pre-insertion counselling}

In Gwent, many insertions are done on a first visit. Of those patients with complete duration of use data, $38 \%$ (152) had two visits only. To establish how many patients have a separate initial consultation, a subset of 100 case notes was reviewed. Seventy-seven (77\%) patients did not have a preinsertion consultation in a service clinic. Three (3\%) patients attending young peoples' clinics had seen an outreach worker prior to attending clinic. In those who had a pre-insertion visit, 7\% (7) had delayed insertion because the doctor could not be reasonably certain that the patient was not already pregnant. Eight $(8 \%)$ patients were seen in a nurse-led clinic and were referred to a clinic with a doctor. The time taken to attend for insertion from initial visit ranged from 3 days to 1 year.

A pre-insertion visit occurred in $23 \%$ of cases with only $10 \%$ having a doctor visit. Therefore for a 15-minute consultation for 493 patients: $10 \%$ doctor consultation preinsertion $=49.3 \times £ 10.96=£ 540.33 ; 13 \%$ patients nurse consultation pre-insertion $=64.09 \times £ 5.56=£ 356.34$. Total for whole cohort $=£ 896.67$.

\section{Additional visits}

'Check-up' visits invariably included a complaint of a side effect. Visits for other reasons were not included (e.g. cervical cytology, collecting condoms). There were 173 additional doctor visits and 251 nurse visits. Almost a third (141, 29\%) of patients complained of irregular bleeding. This was only noted if it was complained of, and not if in the case notes per se. 


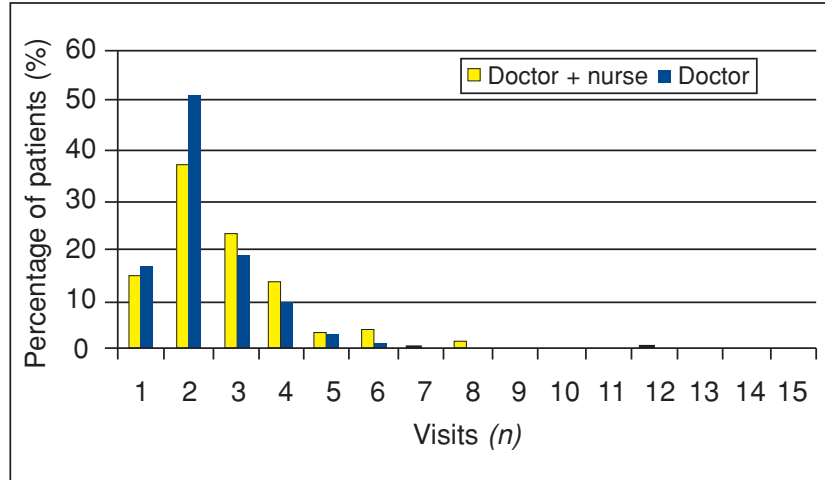

Figure 2 Number of visits per patient

Figure 2 shows the total number of visits per patient. The maximum number of doctor visits was seven. The maximum number of visits to both a doctor and a nurse was 15. Additional visits to the doctor were generally for bleeding problems and to the nurse for pregnancy test requests as a result of amenorrhoea.

\section{Complex removal}

One patient required a general anaesthetic for removal. The cost of the removal was assumed to be the same as the NICE tariff for a STOP procedure. ${ }^{3}$

\section{Indirect costs}

\section{Cost of training}

Cost for training in the NICE Guideline was estimated as $£ 795$ per doctor as a non-recurring cost. In Gwent, all doctors had the Diploma of the Faculty of Sexual and Reproductive Healthcare (DFSRH). The four staff grade doctors requiring training in 2003 were not paid for additional sessions but attended in-house training sessions in place of one of their existing sessions. No doctor attended an external theoretical training course. The trainer cancelled clinics to do the training resulting in lost clinics. The calculated cost of training is therefore three sessions per doctor and an assumption that the trainer is working at around $50 \%$ of the usual throughput. Total one-off cost to the service: 18 trainee sessions +9 trainer sessions $=£ 4143.96$.

\section{Pregnancy during use}

There were three pregnancies diagnosed in women who had Implanon inserted. These were undiagnosed at insertion but it was thought reasonably certain that the women were not pregnant and had a negative pregnancy test at the time of insertion. Dates of the pregnancies confirmed that conception was likely to have occurred prior to insertion. There were no pregnancies that were ascribed to a failure of the contraceptive method.

Table 4 Summary of costs associated with Implanon ${ }^{\circledR}$ provision

\begin{tabular}{ll}
\hline Parameter & Cost $(£)$ \\
\hline $\begin{array}{l}\text { Total costs for insertion and removal + } \\
\text { additional visit + prescriptions + pregnancy or }\end{array}$ & $£ 72,134.03$ \\
general anaesthetic removal cost & \\
Indirect costs: training cost & $£ 4,143.96$ \\
Pre-insertion visits & $£ 896.67$ \\
Total cost of cohort & $£ 77,174.66$ \\
$\begin{array}{l}\text { Divided by } 493 \text { individuals (average total cost } \\
\text { per patient) }\end{array}$ & $£ 156.54$ \\
$\begin{array}{l}\text { Divided by } 2.02 \text { years of use (average annual } \\
\text { cost per patient) }\end{array}$ & $£ 77.49$ \\
Individual cost if lost to follow-up group excluded & $£ 80.74$ \\
\hline
\end{tabular}

The implant was removed in all cases. Two pregnancies were terminated (first trimester) and the COC was prescribed post-abortion. The other woman continued to a full-term normal delivery and an implant was prescribed postnatally. These pregnancies were included in the cost calculations ( $£ 552$ for STOP and $£ 2811$ for birth, NICE tariffs).

\section{Incomplete datasets}

Some $19 \%$ of patients had incomplete duration of use data. Ten $(2 \%)$ patients of those with incomplete data had specifically requested no contact with them or their GP. Patients were not contacted if they were still minors at the time of data collection, recorded as looked-after children or known to be illiterate $(n=6)$. All of the $19 \%$ who were lost to follow-up were given a minimal cost that assumes insertion and removal within the service.

\section{Patients with complete data with lower than predicted costs}

Seven $(1 \%)$ patients were known to have moved out of the area and had removal elsewhere. Five $(1 \%)$ patients had retained their Implanon for longer than 36 months and did not want removal. Four patients were aware that the Implanon had expired and offered uncertain contraceptive efficacy. Their actual costs were calculated (without removal costs).

\section{Cost summary}

The final cost calculation is summarised in Table 4. The range of individual costs varied from $£ 101.76$ to $£ 701.15$ for insertion, removal (including those under anaesthetic) and visits for side effects [mean $£ 133.83$, median $£ 128.42$, interquartile range (IQR) $£ 13.89$, standard deviation (SD) 32.31]. Including pregnancy costs, the range was $£ 101.76$ to $£ 2950.54$ (mean £146.31, median £133.98, IQR £13.89, SD £424.04). Including pre-insertion visits and training costs, the average total cost per patient was $£ 156.54$ and the average annual cost per patient was $£ 77.49$.

\section{Discussion}

The Gwent annual average cost of $£ 77.49$ compares to $£ 103$ estimated by NICE - a difference of $24 \%$. We attempted to measure all direct costs involved with provision of Implanon and have followed the NICE cost impact guideline. Additional costs calculated (e.g. treatment costs and additional visits for side effects of the method) were not included in the NICE Guideline.

Although this article attempts to accurately cost the provision of Implanon, there are a number of limitations that could underestimate the true cost or may not be transferable to other services.

Staff costs are the largest financial cost to contraceptive services. Our staff costs were much lower than calculated in the NICE guidelines. The cost of doctors' time in Gwent was calculated using the highest point for staff grades and consultants per session. In Gwent, the nurses are paid at an F Grade (Band 6 Agenda for Change), not at Band 7 as used in the NICE calculation. This is typical of most contraception and sexual health services that are led by a consultant or associate specialist and have a team of staff often working at less than full time..$^{5}$

The NICE Guideline cost template quotes $£ 2.24$ per minute for doctors' costs based on Curtis et al. ${ }^{6}$ This includes many elements on an annuitised basis such as practice expenses, qualification costs, capital expenditure on premises and equipment and other overheads. This also includes direct care staff costs (equivalent to 0.43 practice nurse to one whole-time equivalent doctor) whereas our 
calculation of nurse costs is separate. It would not be possible for us to calculate and incorporate costs of management, premises and other overheads. Our costs may therefore not translate to the primary care setting. Within our service there was no increase in staff to deal with the expected rise in the provision of LARC. We do have additional overheads such as other staff (clerks, outreach workers), computer and travel expenses as part of the service. Staff costs within this study are based on time for direct patient contacts and do not take into account other duties such as setting up clinics.

Only visits to our service were included. It is known that more women visit their GP for contraception than attend family planning services. ${ }^{7}$ However, our local prescribing data indicate that insertion and removal of Implanon is almost exclusively provided by the sexual health service in our area. It was therefore assumed that patients would have their Implanon removed within the service. It is not known how many patients have moved out of area. It was not possible to calculate number of visits to the GP for side effects and these data were not relevant to the cost calculation for our service. However, a local audit of 473 attenders to clinics in one of the five Local Health Boards indicated that only $17 \%$ had visited their GP for contraception in the previous 6 months and $30 \%$ in the previous 18 months. If there were many visits to the GP for Implanon side effects, the cost of provision to the health community would be higher, though it would not impact on the GSRH service costs.

Nineteen percent of the cohort was lost to follow-up. We have included this group as we know that they had Implanon inserted and we know that our service is the most likely service to remove the Implanon. The only assumption is the cost of their removal and we have used the duration of use of the majority for the cost calculation. If this group is excluded from the cost analysis then the annual cost per user rises by $£ 3.25$ per person to $£ 80.74$.

Some of the costs incurred might not be borne by the Implanon provider such as pregnancy costs or complex removals. In our study, three pregnancies and one removal under general anaesthetic were included in the cost analysis. The termination costs and removal were met by the service directly and the live birth by the Trust to which the service belongs.

In the NICE unit costs, three doctor visits were included: the initial consultation, a consultation for insertion and a follow-up visit for removal. In our direct cost calculations, shorter insertion times and lack of preinsertion consultations reduced the overall time spent with patients as compared to the three visits assumed in the NICE Guideline. Much of the work in open-access clinics is done opportunistically and attempts are made to make clinic visits a 'one-stop shop'. As long as the doctor is reasonably certain there is no risk of pregnancy, an Implanon can be inserted at any time of the cycle. Our analysis indicated that $77 \%$ of our cohort did not have a pre-insertion visit. The relationship between pre-insertion visits and compliance could not be calculated, nor is it known how many patients who have pre-insertion visits then chose a different method. However, all staff have a checklist in which side effects must be fully discussed prior to insertion.

The actual length of consultations for removal and insertion has been measured as part of local work within our service on mapping the patient pathway through clinic. ${ }^{4}$ It is not known if those patients having a preinsertion visit then take less time for a fitting and therefore the standard time calculated from patient pathway study was taken. The lower number of visits of shorter duration in our cohort compared to the assumed number of visits in NICE reduces the cost of provision dramatically. For example, the NICE first year cost for insertion was $£ 175.04$ compared to GSRH cost of $£ 101.76$.

Additional visits were all for side effect complaints. In 2003 it was common practice to offer a 3-month follow-up visit following insertion. However, it appears that women only attended if they had a problem. There were no visits at 3 months in which a side effect was not mentioned by the patient. Regular follow-up visits may increase compliance, ${ }^{8}$ but current practice is an invitation to attend if there is a problem or for removal at 36 months' use.

Prescribing costs were not calculated within the NICE Guideline. In other cost effectiveness calculations, ${ }^{9}$ treatment of side effects is assumed to be removal of method. However, this was not always the case in our service and therefore actual prescribing was included as well as removal costs, which are already included in the unit cost of the method.

At the time of this review only doctors were fitting Implanon in GSRH. Since then, nurses have been trained to fit and remove Implanon, which will decrease costs to the service. It is not known whether nurses will take the same length of time as doctors, however the staff cost differential is such that substantial savings are likely.

NICE Clinical Guideline 30 predicts an average duration of use based on 100 women starting the method and predicted numbers discontinuing the method each year to arrive at a weighted average duration. Discontinuation rates used for the guideline were $43 \%$ over 3 years compared to $63 \%$ in Gwent.

Duration of use of the Implanon in Gwent was lower than the estimate in the NICE Guideline (i.e. 2.02 years compared to 2.24 years). There was probably a small effect of extra removals at 24 months due to raised body mass index, which used to be common practice, with twice the average number of monthly removals occurring in Month 24 . However, the continuation rate fell steadily over the 3year period. Other studies have found that discontinuation rates are also higher than NICE predicted. ${ }^{10}$

Almost a third $(30 \%)$ of patients had their implant removed for side effects. Of these, $68 \%$ did not receive a treatment for their side effects. Lack of treatment of side effects may give a lower duration of use. The COC and non-steroidal anti-inflammatory drugs may be used to treat Implanon-induced bleeding and implementing treatment pathways for common problems may increase duration of use.

Prescribing costs for side effects are low and average less than $£ 0.90$ per patient per 3 years. Many of the nurse visits were primarily for reassurance about irregular bleeding and some for amenorrhoea. Pregnancy tests are sometimes requested because of amenorrhoea and were therefore costed in this study if done.

The 2003 cohort in our service had only 493 subjects who had Implanon that year with unrestricted prescribing. Coinciding with the NICE Guideline on LARC, the use of these methods within the service has increased, most evidently with Implanon. At a total 3 -year cost of $£ 80000$ for Implanon at 2005 costs, this method represents a considerable financial burden on the service. Increased use of the method has led to around 1400 prescriptions in 2007 with an estimated cost of just under $£ 224000$.

Attempts to lower costs include training nurses to fit and remove Implanon and taking advantage of decreased unit costs for Implanon with bulk buying arrangements. The current cost of the implant is about $£ 10$ less than it was in the cohort described in this article. 


\section{Conclusions}

Implanon is a highly effective method of contraception. ${ }^{11}$ Although in the GSRH the average continuation use was less than that predicted by NICE, $37 \%$ of patients continued the method to 36 months. The side effects of Implanon may be managed medically at low cost. Sexual health services offer good use of resources by providing LARC at lower than predicted cost. However, even with an actual average annual cost price $25 \%$ lower than the NICE Guideline calculated cost, the financial burden of LARC provision on services is considerable. Further work needs to be done comparing the actual costs of LARC methods with those of oral contraception.

\section{Acknowledgement}

The authors thank Hayley Jones for data collection.

Statements on funding and competing interests

Funding None identified.

Competing interests Clare Lipetz has received honoraria from Bayer Schering Pharma for teaching engagements.

\section{References}

1 National Institute for Health and Clinical Excellence. LongActing Reversible Contraception (Clinical Guideline CG30). October 2005. http://www.nice.org.uk/Guidance/CG30/ Guidance/pdf/English [Accessed 5 July 2008].

2 Department of Health Statistical Bulletin. Abortion Statistics, England and Wales: 2006. http://www.statistics.gov.uk downloads/theme_health/Conceptions2006/annual_conceptio ns_2006.xls [Accessed 5 July 2008].

3 National Institute for Health and Clinical Excellence (NICE).
National Cost Impact Report: Implementing the NICE Guideline on Long-Acting Reversible Contraception. December 2005. http://www.nice.org.uk/nicemedia/pdf/CG030costing.pdf [Accessed 5 July 2008].

4 Mapping the Patient Pathway (unpublished departmental data). Gwent, UK: Gwent Sexual and Reproductive Health, 2006.

5 Faculty of Sexual and Reproductive Health Workforce Planning Committee. The Ninth and Tenth Census of the Family Planning Workforce in the United Kingdom 2005 and 2006. January 2007. www.ffprhc.org.uk/admin/uploads/ CENSUS0506.pdf [Accessed 5 July 2008].

6 Curtis L, Netten A. Unit Costs of Health and Social Care 2004. Canterbury, UK: Personal Social Services Research Unit, University of Kent at Canterbury, 2004.

7 Department of Health. Sexual health general information: contraception. 2009. http://www.dh.gov.uk/en/Publichealth/ Healthimprovement/Sexualhealth/Sexualhealthgeneralinformat ion/DH_4001998 [Accessed 5 July 2008]

8 Rai K, Gupta S, Cotter S. Experience with Implanon ${ }^{\circledR}$ in a north-east London family planning clinic. Eur $J$ Contracept Reprod Health Care 2004; 9: 39-46.

9 Varney S, Guest J. Relative cost effectiveness of DepoProvera injection, Implanon and Mirena in reversible long term hormonal contraception in the UK. Pharmacoeconomics 2004; 22: 1141-1151.

10 Lakha F, Glasier A. Continuation rates of Implanon ${ }^{\circledR}$ in the UK: data from an observational study in a clinical setting. Contraception 2006; 74: 287-289.

11 French RS, Cowan FM, Mansour DJ, Morris S, Procter T, Hughes D, et al. Implantable contraceptives (subdermal implants and hormonally impregnated intrauterine systems) versus other forms of reversible contraceptives: two systematic reviews to assess relative effectiveness, acceptability, tolerability and cost-effectiveness. Health Technol Assess 2000; 4(7)i-v: 1-107.

12 Armstrong N, Cavey C, Donaldson C. The Economics of Sexual Health. London, UK: fpa, 2005.

\section{FACULTY OF SEXUAL \& REPRODUCTIVE HEALTHCARE MEMBERSHIP EXAMINATION}

The Membership Examination (MFSRH) consists of:

\section{$\square$ Part 1 Multiple Choice Question paper (MCQ)}

This 11/2-hour paper consists of 60 clinical science and applied science questions.

The London based examination will be on Friday 16 October 2009 (the Faculty must receive applications by 1 July 2009 ). The application form and information on the Part 1 can be obtained from the Faculty of Sexual and Reproductive Healthcare (FSRH) website (www.fsrh.org).

\section{$\square$ Evidence Based Commentary (EBC)}

The Evidence Based Commentary replaces the case reports/dissertation component of the Membership examination and candidates can now view the first annually released topic on the Faculty website. Candidates have an absolute deadline of $\mathbf{3 1}$ August 2009 to submit the Commentary on this topic. The Commentary must be a minimum of 1000 words and a maximum of 2000 words, excluding references, tables and appendices, and the format must follow the guidance notes. Candidates can find detailed information in the Candidate Guidance Notes for Evidence Based Commentary and the Membership Examination Regulations (September 2008) on the Faculty website.

\section{口 Part 2 Examination (CRQ, SAQ, OSCE)}

This all-day examination consists of:

- Critical Reading Question examination paper (CRQ)

- Short Answer Question examination paper (SAQ)

- Objective Structured Clinical Examination (OSCE)

The Faculty must receive applications for the MFSRH Part 2 held in June 2010 by 3 January 2010. Information on the Part 2 examination, the Examination Regulations and the application form appear on the Faculty website.

The qualification is subject to re-certification every 5 years.

For the current MFSRH Examination Regulations (September 2008), information on all components of the MFSRH examination and application forms, please visit the FSRH website: www.fsrh.org (see Training \& Exams, Membership Exam) or e-mail Denise Pickford at denise@fsrh.org

\section{JOIN THE PANEL OF MFSRH EXAMINERS}

The Faculty Examination Committee invites applications to join the panel of MFSRH Examiners for the Membership Examination. Further information and the examiner CV application form are available on the FSRH website: www.fsrh.org (see Training \& Exams, Membership Exam, MFSRH Examiners). The closing date for applications is Friday 15 May 2009 and the form should be sent to the Examination Secretary, Examinations, Faculty of Sexual and Reproductive Healthcare of the Royal College of Obstetricians and Gynaecologists, 27 Sussex Place, Regent's Park, London NW1 4RG, UK. Tel: +44 (0) 2077245629 . Fax: +44 (0) 2077235333. 